\title{
Subsidy by Ascophyllum nodosum increases growth rate and survivorship of Patella vulgata
}

\author{
Andrew J. Davies ${ }^{1,2, *}$, Mark P. Johnson ${ }^{1,3}$, Christine A. Maggs ${ }^{1}$ \\ ${ }^{1}$ School of Biological Sciences, Queen's University, 97 Lisburn Road, Belfast BT9 7BL, UK \\ ${ }^{2}$ Present address: Scottish Association for Marine Science, Dunstaffnage Marine Laboratory, Oban, Argyll PA37 1QA, UK \\ ${ }^{3}$ Present address: The Martin Ryan Marine Science Institute, National University of Ireland, University Road, Galway, Ireland
}

\begin{abstract}
Limpets, predominantly Patella vulgata, have been associated with damaged or receding canopies of Ascophyllum nodosum. Although damage results from limpet grazing, the benefits that limpets gain from this behaviour are unclear as A. nodosum is thought to be well defended from grazers by anti-herbivore compounds. In the present study, $P$. vulgata individuals were enclosed at densities between 80 and $320 \mathrm{~m}^{-2}$ at 2 sites within Strangford Lough, Northern Island. Limpet growth and limpet survival were compared between unsubsidised controls and treatments in which limpet diets were subsidised by fronds of $A$. nodosum. When subsidised, limpet residual growth rates were significantly higher and mortality was lower than in unsubsidised control treatments. Individual limpets consumed a similar amount of A. nodosum regardless of limpet density. Higher densities of limpets, therefore, consumed more $A$. nodosum per replicate. The effects of $A$. nodosum in maintaining limpet densities could resonate through sheltered rocky communities. The importance of a macroalgal subsidy in supporting limpet populations may have been underestimated or overlooked in earlier studies. Therefore, the extensive and productive macroalgal canopies that characterise many sheltered temperate rocky shores could be more sensitive to increased limpet abundances than previously thought.
\end{abstract}

KEY WORDS: Limpets · Grazing $\cdot$ Fucoid $\cdot$ Subsidy $\cdot$ Biomass $\cdot$ Phlorotannin - Resale or republication not permitted without written consent of the publisher

\section{INTRODUCTION}

Research on rocky shore communities has often concentrated on the community-structuring effects of grazers. In the intertidal zones of the NE Atlantic, the term 'grazer' is often synonymous with the common limpet Patella vulgata (Coleman et al. 2006). P. vulgata are generalist herbivores that can reach high abundances on the rocky shore (Hawkins \& Hartnoll 1983). Aside from broadscale influences on larval supply and recruitment (Bowman \& Lewis 1986), a number of site-related factors may also influence limpet populations on the shores of northern Europe. Limpet movement and recruitment can be restricted through interactions with the algal canopy and understory (Jenkins et al. 1999). Crab claw marks on wax replica limpets provide evidence of the potential importance of predation on limpet populations (Thompson et al. 2000a), whilst the clumping behaviour of $P$. vulgata has been taken as evidence of a selective pressure to reduce predation risk (Coleman et al. 1999). Finally, per capita reductions in food availability can lead to starvation and mortality (Thompson et al. 2000b, Boaventura et al. 2002, 2003). Although limpets can survive for short periods on stored food reserves (Santini et al. 1995), they will eventually starve and die (Thompson et al. 2000b). The onset of starvation sometimes leads to mass migration, as limpets seek alternative food sources (Loppens 1922, Southward \& Southward 1978). Limpets are considered to preferentially graze on microalgal biofilms (Hawkins \& Hartnoll 1983). A consequence of seasonal variability in microalgal abundance is a potential mismatch between grazing activity and resource availability (Thompson et al. 2000b). This may cause limpet populations to decrease in response to hot summers when benthic microalgal production is low (Thompson et al. 2000b). 
Observations of limpets grazing on fucoid algae (Fischer-Piette 1948, Southward 1964, Southward \& Southward 1978, Le Roux 2005, Davies et al. 2007, Lorenzen 2007) are at odds with the view that macroalgal production 'predominantly' enters detrital food chains (Thompson et al. 2004). Grazing of Ascophyllum nodosum fronds is also slightly unexpected, due to the presence of anti-herbivore compounds that have been shown to deter some species of grazers (Norton et al. 1990, Pavia \& Toth 2000, Borell et al. 2004). If limpets regularly consume macroalgae, then the mismatch hypothesis of Thompson et al. (2000b) may only apply to shores where this alternative food supply is not available. It remains to be demonstrated that consumption of $A$. nodosum actually benefits Patella vulgata. However, Bustamante et al. (1995) showed that subsidies from subtidal kelp maintained high densities of limpets on some South African shores.

The present study used experimental manipulation of Patella vulgata populations to test whether subsidy by Ascophyllum nodosum can benefit P. vulgata. Growth and mortality of limpets were compared between subsidised and control treatments. The algal biomass consumed per limpet was also estimated to test for densityrelated changes in consumption patterns.

\section{MATERIALS AND METHODS}

Study area. Strangford Lough, Northern Ireland, is a sheltered marine lough connected to the Irish Sea by a narrow entrance to the south. The rocky shores in the area are typical of temperate NW European communities, including moderately exposed shores with barnacles and limpets and sheltered shores dominated by Ascophyllum nodosum (L.) Le Jolis (Brown 1990). Horse Island $\left(54^{\circ} 28^{\prime} 46.80^{\prime \prime} \mathrm{N}, 5^{\circ} 32^{\prime} 16.80^{\prime \prime} \mathrm{W}\right)$ and Marlfield Bay (54²4' 28.45" N, 5³4'38.65"W) have an abundance of $A$. nodosum on lower-shore and midshore rocky outcrops and boulders. In mid-shore, clumps of grazed A. nodosum are found along with high densities of the common limpet Patella vulgata L. (see Davies et al. 2007). When the study was carried out, the natural background densities of limpets at the selected sites were $116 \mathrm{~m}^{-2}$ at Horse Island and $124 \mathrm{~m}^{-2}$ at Marlfield Bay, on a par with reports from Orkney $\left(110 \mathrm{~m}^{-2}\right.$; Baxter 1982) and higher than at Plymouth (79 $\mathrm{m}^{-2}$; Hawkins \& Hartnoll 1983) and the Isle of Man (23 to 67 individuals $\mathrm{m}^{-2}$ bare space; Jenkins et al. 1999).

Experimental design. Between August 2003 and June 2004, varying densities of limpets were enclosed within experimental cages $\left(0.0625 \mathrm{~m}^{2}\right)$ to control their available food resources and movement (Thompson et al. 2000b). Cages were constructed from uncoated steel garden mesh (mesh size: $1 \mathrm{~cm}^{2}$ ) with walls $25 \mathrm{~cm}$ long, secured into a square using plastic cable ties. The fences were $3 \mathrm{~cm}$ high and included a $2 \mathrm{~cm}$ wide lip that improved attachment to the rock surface. Each area that was enclosed contained cropped Ascophyllum nodosum individuals and enough limpets to constitute the highest density treatment, removing the need for transplantation of limpets to create high densities due to low reattachment survival (Thompson et al. 2000b).

Limpet density treatments were assigned at random to the caged limpets. The Ascophyllum nodosum plants were removed and Patella vulgata individuals were randomly removed to create densities of 20, 15, 10 , or 5 limpets with shell lengths of 1.7 to $5.25 \mathrm{~cm}$ (mean: $3.5 \mathrm{~cm}$ ) in each quadrat. These numbers represent densities from normal ( 80 to $160 \mathrm{~m}^{-2}$ ) to high (240 to $320 \mathrm{~m}^{-2}$ ). By way of comparison, Thompson et al. (2000b) considered 146 limpets $\mathrm{m}^{-2}$ as a background density, and Boaventura et al. (2002) considered 80 limpets $\mathrm{m}^{-2}$ as a mean density at their study sites. For each limpet density, there were 2 treatments, one subsidised by $A$. nodosum and the other receiving no subsidy. There were 3 replicates of each treatment at each density on each shore.

Subsidised treatments contained an individual frond of Ascophyllum nodosum collected at random from nearby stands. Selected fronds were standardised to $45 \mathrm{~cm}$ in length from the apical tip downwards and were mostly free of diatoms and other epiphytes (Cundell et al. 1977). The frond was hand dried in the field using paper towels and weighed using a battery-powered digital balance $( \pm 0.1 \mathrm{~g})$. Fronds were changed weekly, with the frond reweighed and remaining length recorded in the field prior to being replaced with a new frond. Procedural controls in the form of empty enclosures were used to detect changes in $A$. nodosum mass due to desiccation, physical damage and other factors.

The experiment consisted of 3 different factors: (F1) density: 5, 10 and 20 limpets; (F2) Ascophyllum nodosum: presence and absence within a treatment; and (F3) site: 2 sites within Strangford Lough (Horse Island and Marlfield). The dependent variables recorded for this experiment were: (1) limpet length, (2) limpet mortality within treatment, and (3) total mass of A. nodosum gained or lost. Each individual treatment was replicated 3 times per shore, producing a total of 48 individual cages (in addition, there were 12 control cages containing zero limpets).

Data collection and analysis. To track growth and mortality over time, caged limpets were individually tagged during low tide using an embossed marking system on plastic tape (Dymo). A small area of each limpet shell was roughened and cleaned using sand- 
paper, and a label was attached using cyanoacrylate glue (Loctite). Once the label adhered to the shell, a second application of glue was used to further secure and waterproof the tag. These tags were maintained throughout the experiment and were replaced as necessary. The size of each individual limpet (length and width) was recorded at the start of the experiment and every 2 mo. Growth rate $(r)$ was calculated after Boaventura et al. (2002), as shown in Eq. (1):

$$
r=\frac{\ln \left(L_{\mathrm{end}} / L_{\text {start }}\right)}{t}
$$

where $L_{\text {end }}(\mathrm{cm})$ is shell length at the end of the experiment, $L_{\text {start }}(\mathrm{cm})$ is the length at the beginning of the experiment and $t$ is the experimental duration (days). Limpet mortality was recorded at weekly intervals and, in the present study, was defined as being missing from the enclosed area.

Variation in the size of enclosed limpets at the start of the experiment introduced a source of uncertainty into the data as smaller limpets grow faster than larger limpets (Fig. 1). To adjust for variation in limpet sizes, a second-order polynomial regression line was fitted. This model was selected over linear and log relationships following examination of the residual plots, which were more symmetrical with the polynomial model (adjusted $\mathrm{r}^{2}$ values were also higher for the polynomial). The fitted curve gives the mean growth rate for each possible initial size of limpet (Fig. 1). The deviation from this fitted line was calculated for each limpet, forming a residual growth rate $(R r)$, which shows whether the growth rate of the limpet was better (positive value) or worse (negative value) than the overall mean rate of growth for its initial size.

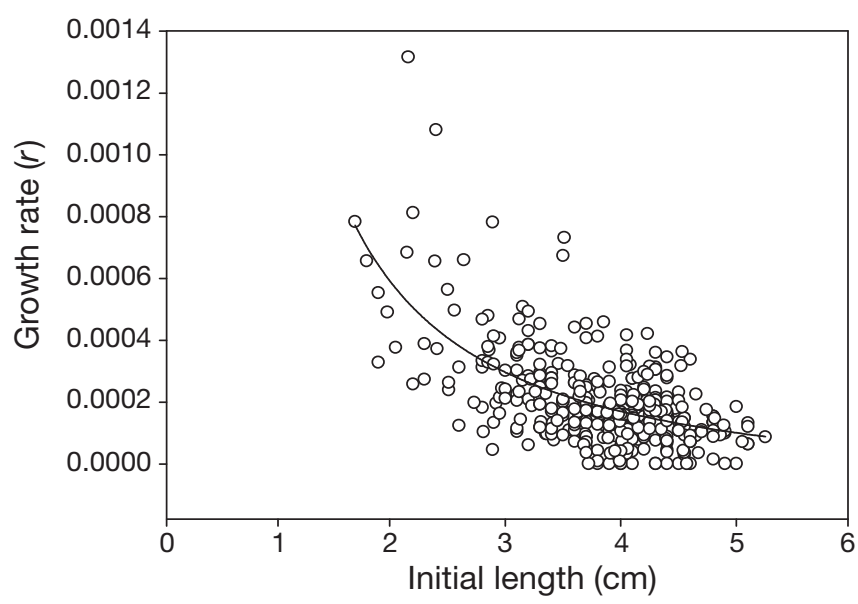

Fig. 1. Patella vulgata. Initial length $(\mathrm{cm})$ plotted against growth rate ( $r$ : logarithmically transformed length increase per day; Eq. 1) at the end of the 10 mo experiment $[\mathrm{n}=378$; growth rate $=\left(0.00006 \times\right.$ length $\left.^{2}\right)-(0.00006 \times$ length $)-0.0015$; $\left.\mathrm{r}^{2}=0.374, \mathrm{p}<0.001\right]$
Growth and mortality were analysed using ANOVA, following tests of the assumption of homogeneity of variances. Site (Horse Island or Marlfield) was treated as a random factor to test the hypothesis that the main effects of density and subsidy were consistent in space. This design is equivalent to a generalized, randomized block design (Quinn \& Keough 2002) and has the advantage over unreplicated, randomized block designs that the interaction between site (= block) and treatment can be estimated. Despite mortality, average densities in the density treatments did not overlap, so 'density' was used as a fixed factor in analyses (1-way ANOVA on average density per replicate, $F_{3,44}=100.23, \mathrm{p}<0.001$, significant differences among 'density' treatments). As the main effects of density and subsidy were the overall hypotheses of interest, interactions between these factors and site were pooled to increase the power of the analyses if 2 conditions were met: (1) the main effects were not already significant and (2) the interaction term had an estimated probability exceeding 0.25 (Quinn \& Keough 2002). Estimates of Ascophyllum nodosum consumption per limpet could be made for each replicate each week. As the same cages were examined over successive weeks, these estimates were not independent over time. Repeated-measures analysis was not suitable for these data as the interpretation of the seasonal effects is obscured by variation in mortality among cages. In addition, estimates of $R r$ on different dates are not necessarily equivalent: the $R r$ values are not strictly repeated measures as they would be dependent on the fit of a different nonlinear relationship between size and growth within each time period. The average per capita consumption of A. nodosum was therefore calculated for each cage over the entire experiment, meaning that 1 value per cage was used in analyses.

\section{RESULTS}

\section{Limpet growth}

Limpets that were enclosed with Ascophyllum nodosum had a greater than average $R r$ than those that were unsubsidised (Fig. 2, Table 1a: A. nodosum). For each combination of density and site, the subsidised treatments always had the higher mean growth rate. There was no clear effect of density on residual growth. The site interaction reflects no difference among densities at Horse Island, while the 20 limpets per cage treatment had a significantly lower growth rate than other densities at Marlfield (Fig. 2; Student-Newman-Keuls [SNK] tests, p < 0.05). 


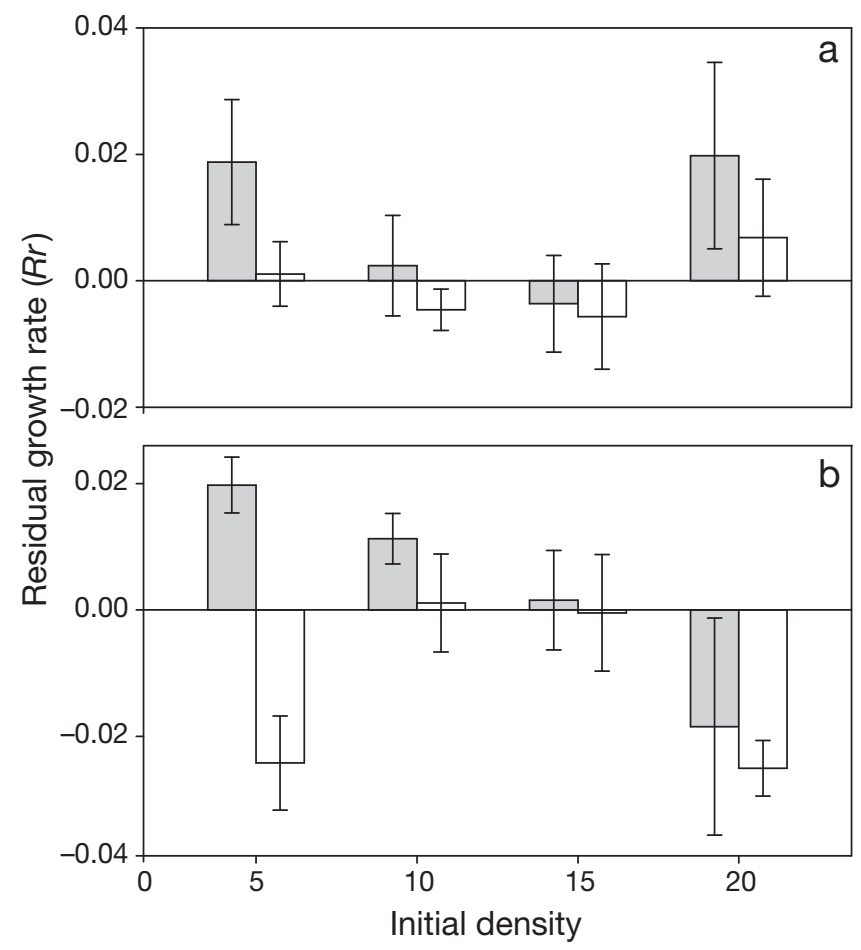

Fig. 2. Patella vulgata. Mean $( \pm \mathrm{SE})$ residual growth rate $(R r)$ in each density treatment, with Ascophyllum nodosum present (shaded bars) and absent (open bars) from (a) Horse Island and (b) Marlfield. Positive values indicate growth rate was better than overall rate of growth for that initial limpet size, and negative values show growth rates that were worse

\section{Limpet mortality}

Mortality over the course of the experiment was significantly related to density (Fig. 3, Table 1b: SNK for density: $20=15>10=5, p<0.05)$. The pattern of increased mortality at higher densities was seen regardless of whether Ascophyllum nodosum was present within the cage or not. The variation in the effect of $A$. nodosum subsidy among density and site treatments was not sufficient to cause an interaction or to obscure the main effect of the subsidy (Table 1b: A. nodosum). The presence of a subsidy reduced the overall mortality compared to unsubsidised treatments (mean mortality of $25 \%$ [SE 4.5] with subsidy compared to $33 \%$ [SE 5.4] without).

\section{Consumption of Ascophyllum nodosum}

In treatments that contained no limpets, there were minor fluctuations in the wet mass of Ascophyllum nodosum, not exceeding $8 \%$ total mass $\mathrm{wk}^{-1}$. This contrasts with ca. $25 \%$ of $A$. nodosum consumed on average in the 5 limpet treatments, rising to ca. $91 \%$ consumption $\mathrm{wk}^{-1}$ at the highest limpet density. There were no significant effects of density on the average per capita consumption of $A$. nodosum (A. nodosum mass lost/density) (2-way ANOVA, site, density and interaction terms not significant). On average, a limpet consumed $0.42 \mathrm{~g}$ (SE 0.007) A. nodosum $\mathrm{wk}^{-1}$.
Table 1. General linear models on (a) residual growth rate $(R r)$ and (b) limpet Patella vulgata mortality at the end of the experiment. Site was a random factor; density and Ascophyllum nodosum were treated as fixed. Significant values are highlighted in bold. In (a) data were untransformed, with the assumption of normality and homogeneity of variances being met (Cochran's $C$-test, $C=0.237, \mathrm{p}$ > 0.05). Pooled terms include the residual variation, the 3 -way interaction and the interaction between subsidy and site. Pooled treatment combinations had $p>$ 0.25 . In (b) data were untransformed, with the assumption of homogeneity of variances being met (Cochran's $C$-test, $C=0.222$, p > 0.05)

\begin{tabular}{|lcccc|}
\hline & df & MS & $F$ & $p$ \\
\hline (a) Residual growth rate & & & & \\
Density & 3 & 0.0002 & 0.15 & 0.923 \\
A. nodosum & $\mathbf{1}$ & $\mathbf{0 . 0 0 2}$ & $\mathbf{1 0 . 0 0}$ & $\mathbf{0 . 0 0 3}$ \\
Site & $\mathbf{1}$ & $\mathbf{0 . 0 0 0 9}$ & $\mathbf{4 . 5 0}$ & $\mathbf{0 . 0 4 1}$ \\
Density $\times$ A. nodosum & 3 & 0.0005 & 2.5 & 0.075 \\
Density $\times$ Site & $\mathbf{3}$ & $\mathbf{0 . 0 0 1 2}$ & $\mathbf{6 . 0 0}$ & $\mathbf{0 . 0 0 2}$ \\
Pooled terms & 36 & 0.0002 & & \\
(b) Limpet mortality & & & & \\
Density & $\mathbf{3}$ & $\mathbf{4 2 7 2 . 7}$ & $\mathbf{2 0 . 3}$ & $\mathbf{0 . 0 1 7}$ \\
A. nodosum & $\mathbf{1}$ & $\mathbf{7 3 8 . 9}$ & $\mathbf{2 6 0 . 6}$ & $\mathbf{0 . 0 3 9}$ \\
Site & 1 & 0.058 & 0.0 & 0.989 \\
Site $\times$ Density & 3 & 210.24 & 0.69 & 0.564 \\
A. nodosum $\times$ Site & 1 & 2.84 & 0.01 & 0.924 \\
Density $\times$ A. nodosum & 3 & 684.3 & 1.11 & 0.466 \\
Site $\times$ Density $\times$ A. nodosum & 3 & 614.87 & 2.02 & 0.131 \\
Residual & 32 & 304.17 & & \\
\hline
\end{tabular}

\section{DISCUSSION}

Consumption of Ascophyllum nodosum reduced Patella vulgata mortality and improved growth rates relative to unsubsidised treatments. These effects occurred even though A. nodosum is considered to be well protected from grazers by the secondary metabolite, phlorotannin (Ragan \& Glombitza 1986). Phlorotannins may serve to reduce herbivore grazing by acting as a deterrent or an inhibitor (Targett \& Arnold 1998). In this study, no negative effects were recorded when $P$. vulgata consumed A. nodosum. Typical phlorotannin concentrations in $A$. nodosum are ca. $5 \%$ of dry weight (Pavia et al. 2003), with the majority of variation in concentration occurring at small spatial scales (within genets rather than between geographical areas; Pavia et al. 2003). It therefore seems unlikely that $A$. nodosum within 


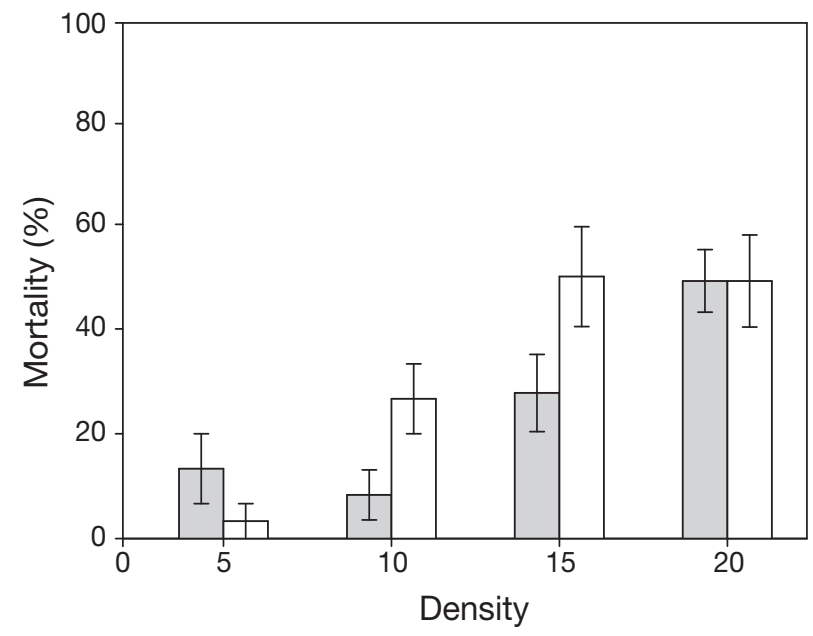

Fig. 3. Patella vulgata. Mean $( \pm \mathrm{SE})$ mortality in each density at the end of the experiment, with Ascophyllum nodosum present (shaded bars) and absent (open bars)

Strangford Lough lack phlorotannins, and the net benefits of macroalgal consumption for $P$. vulgata are likely to result despite their presence.

The ecological role of macroalgal consumption by Patella vulgata is unclear. Recognition of this role implies that the paradigm of a detrital pathway for intertidal macroalgal production (Thompson et al. 2004) may have to be reconsidered. In some situations, consumption of fucoids by limpets has been implicated in loss of the canopy (Southward \& Southward 1978, Le Roux 2005, Davies et al. 2007, Lorenzen 2007). Such reductions in canopy cover may be due to factors that have led to local increases in limpet abundances. Johnson \& Hawkins (1998) pointed out that, even with a simple model, increases in limpet number can result from a number of processes, most of which have not been discriminated simultaneously. Hence, the explanations for changes in limpet populations include increases in recruitment due to algal facilitation or milder climates (Southward \& Southward 1978, Davies et al. 2007), changes in mortality due to reduced harvesting, eutrophication facilitating recruitment, and reductions in populations of crab predators of limpets (Lorenzen 2007).

Results on per capita consumption of Ascophyllum nodosum imply that grazing on macroalgae is not due to switching to a less favoured food when the main resource (biofilm) is depleted. If this were the case, then the A. nodosum consumption per limpet would increase with increasing density. Consumption therefore occurs whenever Patella vulgata encounters $A$. nodosum.

As would be expected under increased intraspecific competition, limpet mortality increased with density (Thompson et al. 2000b, Boaventura et al. 2002). The results for relative growth rate were, however, less consistent. At one site there was a reduced mean growth at high density, but generally, residual growth estimates did not differ among treatments. Insufficient information on the ecological differences between sites is available to speculate on the causes of the interaction. In part, the apparently weak density effects on growth may be due to the experimental design. Previous limpet enclosure experiments used narrower size ranges of individuals (Thompson et al. 2000b, Boaventura et al. 2002, 2003). This will have reduced variability among replicates to a greater extent than the analysis of residuals used in the current study. A further source of experimental variability was drift algae. Unattached fragments of algae are also eaten by limpets (Lorenzen 2007) and were occasionally found caught on the cage sides. There is no reason to assume that the capture of drifting algae varied among replicates in anything but a random pattern, but this additional unpredictable food resource will have increased the variability in measured growth and mortality rates.

The benefits of eating macroalgae are likely to lead to increased limpet populations in areas with access to algae or relatively high inputs of drifting material. This assumes that macroalgal consumption does not reduce fecundity, as in Littorina obtusata (Toth et al. 2005). Unlike the direct-developing L. obtusata, however, Patella vulgata has planktonic larvae. This reduces the scope for local reductions in fecundity to affect local population size as larvae can recruit from a wide range of source populations. The stability of subsidised populations of $P$. vulgata is not clear. Consumption of established canopies occurs over decades (Davies et al. 2007), so enhanced populations of limpets may persist for a long time. Algal canopies have been ascribed both positive and negative effects on limpet recruitment (Southward \& Southward 1978, Jenkins et al. 1999). Such interactions may lead to oscillations or damped oscillations in algal cover (as observed following the Torrey Canyon oil spill clean up, Southward \& Southward 1978; and in simulations using the model of Johnson \& Hawkins 1998). In cases where the oscillations are provoked by an acute disturbance such as the Torrey Canyon clean up, they may have a periodicity of a few years. In cases such as the decline of cover in Strangford Lough, oscillations in the limpet-macroalgal system (if they exist) are likely to have a period of decades.

These results highlight the importance to Patella vulgata of nutritional subsidy by Ascophyllum nodosum on the shores of Strangford Lough. There is the potential for this to occur on other temperate shores throughout Europe, especially on sheltered shores where limpets and A. nodosum co-occur (Fischer-Piette 1948, Le Roux 2005, Lorenzen 2007, C. A. Maggs, M. T. Bur- 
rows, S. J. Hawkins pers. comm.). When A. nodosum was present, limpets maintained relatively higher densities and benefited from lower mortality and improved growth rates. Both $P$. vulgata and $A$. nodosum are strong regulators of the rocky shore community; disruption to either species can lead to major changes throughout the shore.

Acknowledgements. M. Edwards, G. Hinojosa and F. Mineur assisted with fieldwork. A.J.D. was supported by a DEL scholarship.

\section{LITERATURE CITED}

Baxter JM (1982) Population dynamics of Patella vulgata in Orkney. Neth J Sea Res 16:96-104

Boaventura D, da Fonseca LC, Hawkins SJ (2002) Analysis of competitive interactions between the limpets Patella depressa Pennant and Patella vulgata L. on the northern coast of Portugal. J Exp Mar Biol Ecol 271:171-188

Boaventura D, da Fonseca LC, Hawkins SJ (2003) Size matters: competition within populations of the limpet Patella depressa. J Anim Ecol 72:435-446

Borell EM, Foggo A, Coleman RA (2004) Induced resistance in intertidal macroalgae modifies feeding behaviour of herbivorous snails. Oecologia 140:328-334

Bowman RS, Lewis JR (1986) Geographical variation in the breeding cycles and recruitment of Patella spp. Hydrobiologia 142:41-56

Brown R (1990) Strangford Lough: the wildlife of an Irish Sea Lough. Institute of Irish Studies, The Queen's University of Belfast

Bustamante RH, Branch GM, Eekhout S (1995) Maintenance of an exceptional intertidal grazer biomass in South Africa: subsidy by subtidal kelps. Ecology 76:2314-2329

> Coleman RA, Goss-Custard JD, Le V. dit Durell SEA, Hawkins SJ (1999) Limpet Patella spp. consumption by oystercatchers Haematopus ostralegus: a preference for solitary prey items. Mar Ecol Prog Ser 183:253-261

Coleman RA, Underwood AJ, Benedetti-Cecchi L, Aberg P and others (2006) A continental scale evaluation of the role of limpet grazing on rocky shores. Oecologia 147:556-564

Cundell AM, Sleeter TD, Mitchell R (1977) Microbial populations associated with surface of the brown alga Ascophyllum nodosum. Microb Ecol 4:81-91

> Davies AJ, Johnson MP, Maggs CA (2007) Limpet grazing and loss of Ascophyllum nodosum canopies on decadal time scales. Mar Ecol Prog Ser 339:131-141

Fischer-Piette E (1948) Sur les éléments de prospérité des patelles et sur leur spécificité. J Conchyliol 88:45-96

Hawkins SJ, Hartnoll RG (1983) Grazing of intertidal algae by marine invertebrates. Oceanogr Mar Biol Annu Rev 21: 195-282

Jenkins SR, Hawkins SJ, Norton TA (1999) Direct and indirect effects of a macroalgal canopy and limpet grazing in struc-

Editorial responsibility: Laura Airoldi,

Ravenna, Italy turing a sheltered inter-tidal community. Mar Ecol Prog Ser 188:81-92

Johnson MP, Hawkins SJ (1998) Insights from a general model of herbivores and macroalgae on rocky shores. Oikos 82:603-608

Le Roux A (2005) Les patelles et la régression des algues brunes dans le Morbihan. Penn Bed 192:1-22

Loppens K (1922) Note sur la variabilité et l'éthologie de Patella vulgata. Ann Soc R Zool Belg 53:57-68

Lorenzen S (2007) The limpet Patella vulgata L. at night in air: effective feeding on Ascophyllum nodosum monocultures and stranded seaweeds. J Molluscan Stud 73:267-274

> Norton TA, Hawkins SJ, Manley NL, Williams GA, Watson DC (1990) Scraping a living - a review of littorinid grazing. Hydrobiologia 193:117-138

Pavia H, Toth GB (2000) Inducible chemical resistance to herbivory in the brown seaweed Ascophyllum nodosum. Ecology 81:3212-3225

Pavia H, Toth GB, Lindgren A, Aberg P (2003) Intraspecific variation in the phlorotannin content of the brown alga Ascophyllum nodosum. Phycologia 42:378-383

Quinn GP, Keough MJ (2002) Experimental design and data analysis for biologists. Cambridge University Press, Cambridge

Ragan MA, Glombitza KW (1986) Phlorotannins, brown algal polyphenols. In: Round FE, Chapman DJ (eds) Progress in phycological research, Vol 4. Biopress, Bristol, p 130-241

Santini G, Chelazzi G, Della Santina P (1995) Size-related functional and energetic constraints in the foraging of the limpet Patella vulgata (Mollusca, Gastropoda). Funct Ecol 9:551-558

Southward AJ (1964) Limpet grazing and the control of vegetation on rocky shores. In: Crisp DJ (ed) Grazing in terrestrial and marine environments. Blackwell Scientific Publications, Oxford, p 165-273

Southward AJ, Southward EC (1978) Recolonisation of rocky shores in Cornwall after use of toxic dispersants to clear up the Torrey Canyon spill. J Fish Res Board Can 35: 682-706

Targett NM, Arnold TM (1998) Predicting the effects of brown algal phlorotannins on marine herbivores in tropical and temperate oceans. J Phycol 34:195-205

Thompson RC, Jenkins SR, Bussell JA (2000a) A method for recording predator-prey encounters between crabs and limpets using wax replicas. J Mar Biol Assoc UK 80: 633-638

> Thompson RC, Roberts MF, Norton TA, Hawkins SJ (2000b) Feast or famine for intertidal grazing molluscs: a mismatch between seasonal variations in grazing intensity and the abundance of microbial resources. Hydrobiologia 440:357-367

> Thompson RC, Norton TA, Hawkins SJ (2004) Physical stress and biological control regulate the producer-consumer balance in intertidal biofilms. Ecology 85:1372-1382

> Toth GB, Langhamer O, Pavia H (2005) Inducible and constitutive defenses of valuable seaweed tissues: consequences for herbivore fitness. Ecology 86:612-618

Submitted: November 2, 2007; Accepted: February 5, 2008 Proofs received from author(s): August 12, 2008 